\title{
Energy Efficiency Obligations for Electricity Utilities: Economics and Policy
}

\author{
[ Watsapon Tharana, Athikom Bangviwat ]
}

From the increasing of energy demands in Thailand, it has more effects to the future, for example, energy supply security, increasing energy costs, dependency on energy imports as well as increasing pollution and carbon dioxide $\left(\mathrm{CO}_{2}\right)$ emissions. Consequently, Thai government established 20 years plan which is Energy Efficiency Development Plan (EEDP) to reduce $25 \%$ of energy intensity in 2030 compared to 2005 , this is equivalent to reduce $20 \%$ of final energy consumption in 2030 . In order to support this plan, the benefits of implemented EEDP were analyzed by this paper. However, the analysis is only focused on the benefits from reducing electricity demands in term of saving costs and this paper showed only saving costs from 2014 to 2018. Under assumption, EEDP is aimed to reduce $1 \%$ of electricity demands in every year. As a result, it is estimated to reduce 48,699.37 GWh in 2030, this is equivalent about $60 \%$ from EEDP target of electricity use and the results from available data also showed that it can be create saving costs from 2014 to 2018 about 205,027.59 Million Bath.

Keywords-Energy Efficiency, EEDP, Saving costs, ,Utilities

\section{Introduction}

Energy Efficiency Development Plan (EEDP) was established in 2010 by Thai government. In detail, the Energy Efficiency Development Plan (EEDP) is formulated with a target to reduce energy intensity by $25 \%$ in 2030 , compared with 2005, or equivalent to reduction of final energy consumption by $20 \%$ in 2030 (TABLE I), or about 30,000 thousand tons of crude oil equivalent (ktoe). The EEDP is aimed at reducing energy elasticity, which is the percentage change in energy consumption to achieve a $1 \%$ change in national GDP, from an average of 0.98 in the past 20 years to 0.7 in the next 20 years and Implementation of the EEDP has estimated a result in cumulative energy savings at an average of 14,500 ktoe/year, which is worth 272 billion baht/year, and cumulative $\mathrm{CO} 2$ emission reductions at an average of 49 million tons/year [1].

Mr. Watsapon Tharana

King Monkut's University of Technology Thonburi Thailand

Dr. Athikom Bangviwat

King Monkut's University of Technology Thonburi Thailand
TABLE I. Share of Energy Saving by Economic Sector in 2030 [1]

\begin{tabular}{|c|c|c|c|}
\hline \multirow{2}{*}{ Economic sector } & \multicolumn{3}{|c|}{ Specified Target in 2030} \\
\hline & $\begin{array}{c}\text { Electricity } \\
(\mathbf{G W h})\end{array}$ & $\begin{array}{c}\text { Heat } \\
\text { (Ktoe) } \\
\end{array}$ & $\begin{array}{r}\text { Total } \\
\text { (Ktoe) } \\
\end{array}$ \\
\hline Industry & 39,112 & 12,767 & 16,100 \\
\hline $\begin{array}{l}\text { Large commercial } \\
\text { building }\end{array}$ & 23,007 & 340 & 2,300 \\
\hline $\begin{array}{l}\text { Small commercial } \\
\text { building \& residential }\end{array}$ & 18,972 & 1,383 & 3,000 \\
\hline Total & 81,116 & 31,288 & 38,200 \\
\hline
\end{tabular}

\section{Objective}

In order to support EEDP, the topic of Energy Efficiency Obligations for Electricity Utilities: Economics and Policy is focused on reducing electricity demands of end users which effected on utilities in economic term that utilities can receive the benefits from reducing electricity demands of end users, it was illustrated by saving costs which are received from unnecessary investments.

\section{Theories}

According to the paper of Timothy J. Brennan [2] showed that savings quantity of electricity use can be created by energy efficiency resource standards (EERS).

Let:

- $\mathrm{Q}$ is the quantity of electricity use.

- $\mathrm{B}(\mathrm{Q})$ is the benefit consumers get from using electricity.

- $\mathrm{MC}(\mathrm{Q})$ is the marginal cost of generating that electricity.

- $\mathrm{V}(\mathrm{Q})$ is the value of electricity $(\mathrm{B}(\mathrm{Q})-\mathrm{MC}(\mathrm{Q}))$. Rewrite from $\mathrm{V}(\mathrm{Q})$ to $\mathrm{V}(\mathrm{Q}, \theta)$ for allow $\mathrm{V}(\mathrm{Q})$ to change from outside factors, where $\theta$ is a parameter reflecting exogenous changes in the benefit or cost functions.

- $\mathrm{E}(\mathrm{Q})$ is the external harm associated with electricity generation, to keep matters simple, assume that the external harm from generation (e.g., marginal greenhouse gas effects) is independent of $\theta$, the parameter affecting $\mathrm{V}$.

In the absent of EERS, the quantity of electricity use be $\mathrm{Q}_{\mathrm{BAU}}$ under assumption that cost per unit of marginal external harm is fixed in all of $Q$ value. When implementing EERS with a fixed electricity reduction (Figure 1), the savings quantity of electricity use will be occurred this is different between $\mathrm{Q}_{\mathrm{BAU}}$ and $\mathrm{Q}_{\mathrm{EERS}}$. In addition to, if EERS limits 
electricity use to a fixed percentage below BAU. The savings quantity of electricity use is occurred follow on Figure 2. Moreover, Timothy J. Brennan also analyzed that an EERS is created to reduce electricity use by a fixed amount or fixed percentage relative to BAU would be optimal. Accordingly, this paper is created to show the estimation of EEDP savings in fixed percentage, when EEDP is aimed to limit electricity use with $1 \%$ in every year and the fixed $1 \%$ is received from literature reviews of Energy Efficient Resource Standards: experience and recommendations by Steven Nadel [3].

\section{Methodology}

From power development plan in Thailand [4], the projected of electricity demands, this paper is called BAU case, and contract capacity of power plants from 2012 to 2030 are available. This paper showed both of data which are calculated in term of energy (GWh) as shown in the Figure 3 and Figure 4 respectively.

Firstly, this paper showed the projected EEDP case under assumption that it is aimed to reduce $1 \%$ of electricity demands in every year from 2015 to 2030 by using an average growth rate $(0.37$ percent), which was estimated from PDP data. Consequently, the electricity demands will be decreased in every year and the different electricity demands between BAU case and EEDP case are showed in the figure 5.

Secondly, this paper is analyzed that how savings can be created by implemented EEDP case and it is estimated in term of saving costs. Under assumption, EEDP case is aimed to reduce electricity demands $1 \%$ in every year. However, this paper showed the re-projected EEDP case by adding $15 \%$ of electricity demands in each year for theoretical reserve of electric capacity.

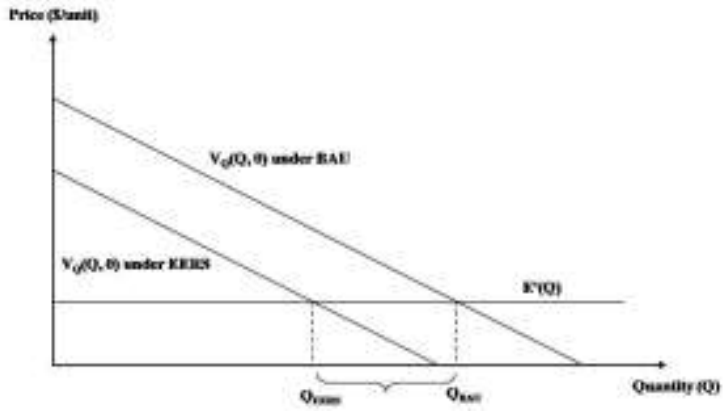

Figure 1. Potential optimality of a fixed-quantity EERS

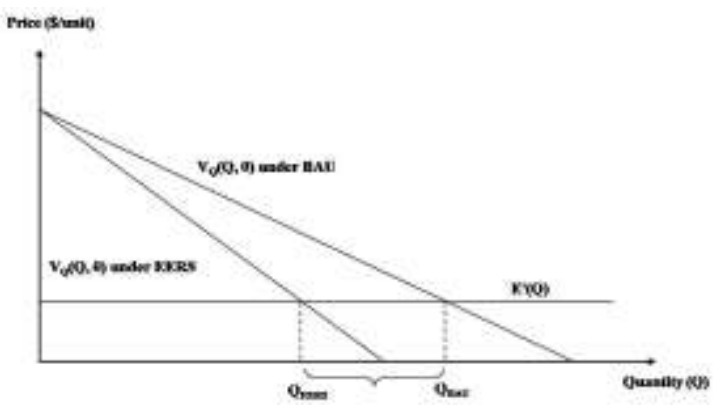

Figure 2. Potential optimality of a fixed-percentage EERS

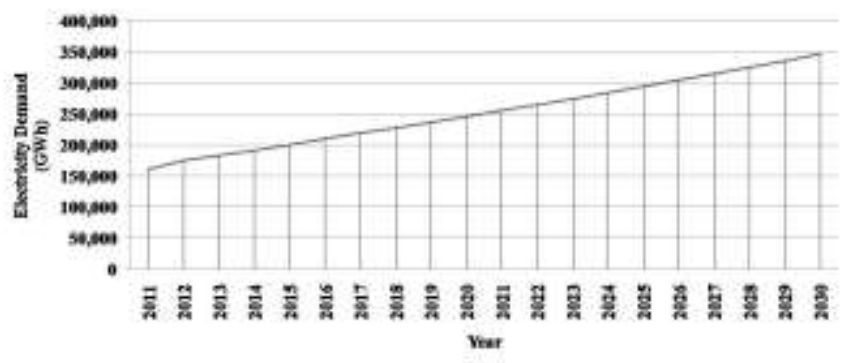

Figure 3. Projected of electricity demands from 2011-2030

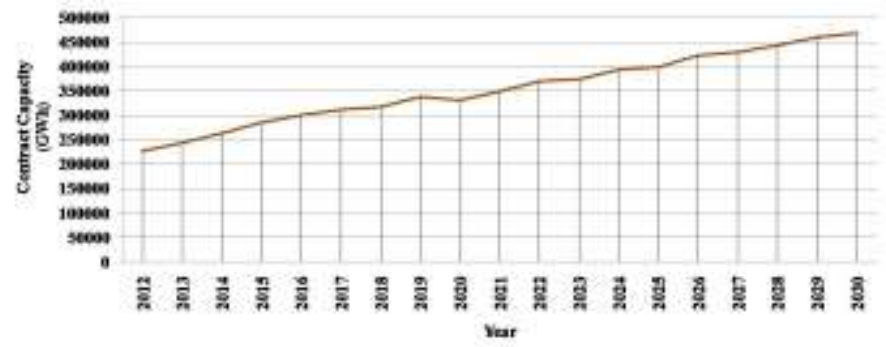

Figure 4. Contract capacity of power plants from 2012-2030

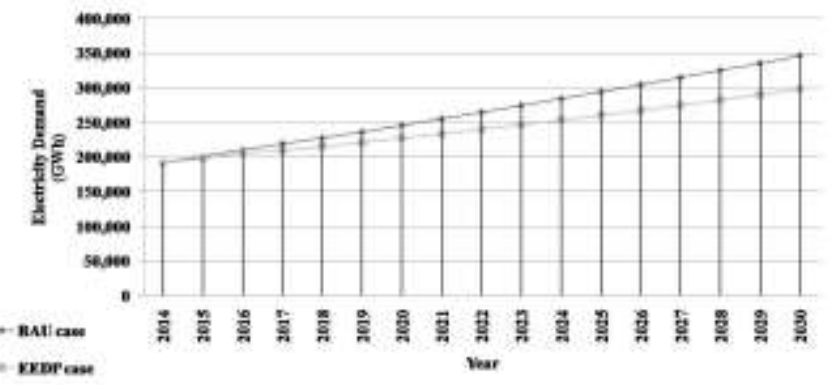

Figure 5. Different electricity demands between BAU case and EEDP case from 2014 to 2030

According to, the idea of estimating saving costs, which can be received from unnecessary capacity of power plants, is occurred. From 2014 to 2018, the Figure 6 indicates that installed capacity of power plants in 2014 can be used till 2017 by unnecessary installing of new capacity from 2015 to 2017. This is because EEDP case is still less than existed capacity except 2018 that EEDP case is higher than existed capacity. Consequently, it must be installed new capacity in 2018 for avoiding lack of power. Where are existed capacity calculated from, existed capacity can be decreased, it depended on retired capacity of power plants in each year. Thus, existed capacity is calculated from installed capacity minus to retired capacity in each year.

Lastly, this paper show the estimation of saving costs from unnecessary capacity from 2015 to 2017 in the topic of analyzed results 
Proc. of the Intl. Conf. on Advances in Applied science and Environmental Technology - ASET 2015.

Copyright (C) Institute of Research Engineers and Doctors, USA .All rights reserved.

ISBN: 978-1-63248-040-8 doi: 10.15224/ 978-1-63248-040-8-34

\section{v. Analyzed Results}

This paper showed an average capital costs in each year of power plants in term of Bath per KWh (Bath/unit), which were calculated by using data of capital costs from Chadinee Kongrahad [5] (Table II) and projection of energy generation by fuel Types from PDP, including $1 \%$ of inflation rate. Therefore this paper can show an average capital costs, followed on the Table III. For understanding, LCOE is levelized cost of electricity from all investment costs, fix and variable O\&M costs, fuel costs, and other costs but the capital cost is only used because this paper is analyzed only investments of new power plants.

Therefore the different capacities between installed capacity in 2014 and contract capacity under PDP in 2015, 2016, and 2017, are saving capacities or unnecessary capacities. The results of saving capacities are showed in the Table IV.

In summary, this paper illustrated that it can be delayed to create new power plants in 2015 to 2018 by unnecessary installing of new power plants from 2015 to 2017 under EEDP case and it is estimated to save total costs of investments from 2015 to 2018 about 205,027.59 Million Bath (Table IV).

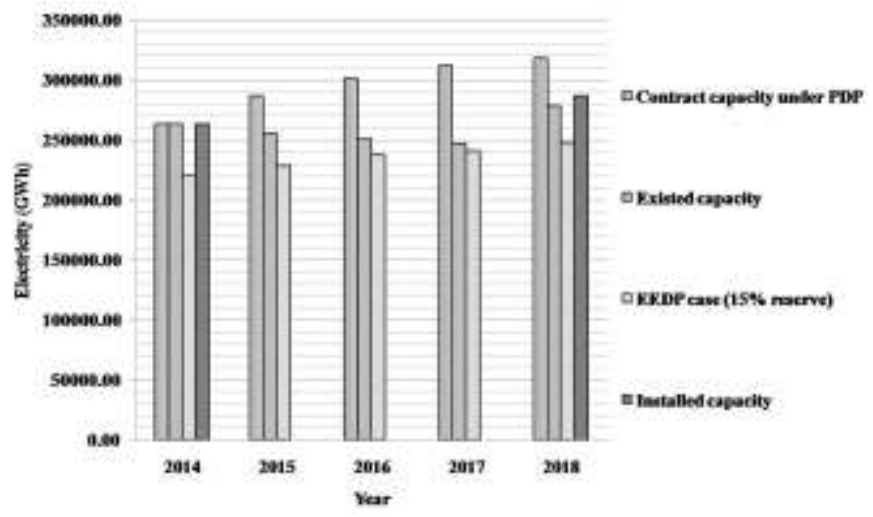

Figure 6. Comparison of capacity from 2014 to 2018

TABLE II. Costs in different type of technology [5]

\begin{tabular}{|l|cccc|}
\hline \multirow{2}{*}{\begin{tabular}{c}
\multirow{2}{*}{$\begin{array}{c}\text { Type of } \\
\text { Technology }\end{array}$} \\
\cline { 2 - 5 }
\end{tabular}} & $\begin{array}{c}\text { Capital } \\
\text { cost }\end{array}$ & $\begin{array}{c}\text { O\&M } \\
\text { cost }\end{array}$ & $\begin{array}{c}\text { Fuel } \\
\text { Cost }\end{array}$ & $\begin{array}{c}\text { LCOE } \\
\text { (Calculation) }\end{array}$ \\
\hline $\begin{array}{l}\text { Reciprocating } \\
\text { diesel engine }\end{array}$ & 0.3 & 0.39 & 10.86 & 11.55 \\
Renewable & 0.79 & 0.72 & 1.96 & 3.46 \\
Thermal-Gas & 0.31 & 0.27 & 2.14 & 2.71 \\
Nuclear & 1.3 & 0.65 & 0.32 & 2.27 \\
Combined cycle- & 0.38 & 0.4 & 1.21 & 1.99 \\
NG & 0.41 & 0.52 & 0.64 & 1.58 \\
Thermal-Coal & 0.61 & 0.17 & 0 & 0.79 \\
Hydro & 0 & - & - & - \\
Import & & & & \\
\hline
\end{tabular}

TABLE III. Capital costs from 2014 to 2030

\begin{tabular}{|c|c|}
\hline Year & Capital Cost (Bath/KWh) \\
\hline 2014 & 1.31 \\
\hline 2015 & 1.40 \\
\hline 2016 & 1.44 \\
\hline 2017 & 1.46 \\
\hline 2018 & 1.45 \\
\hline 2019 & 1.53 \\
\hline 2020 & 1.48 \\
\hline 2021 & 1.48 \\
\hline 2022 & 1.54 \\
\hline 2023 & 1.51 \\
\hline 2024 & 1.52 \\
\hline 2025 & 1.47 \\
\hline 2026 & 1.52 \\
\hline 2027 & 1.51 \\
\hline 2028 & 1.52 \\
\hline 2029 & 1.52 \\
\hline 2030 & 1.51 \\
\hline
\end{tabular}

TABLE IV. Summary of results in savings

\begin{tabular}{|c|c|c|c|c|c|}
\hline & \multicolumn{5}{|c|}{ Year } \\
\cline { 2 - 6 } & $\mathbf{2 0 1 4}$ & $\mathbf{2 0 1 5}$ & $\mathbf{2 0 1 6}$ & $\mathbf{2 0 1 7}$ & $\mathbf{2 0 1 8}$ \\
\hline $\begin{array}{c}\text { Contract } \\
\text { capacity } \\
\text { under PDP }\end{array}$ & $263,185.54$ & $286,565.93$ & $301,485.27$ & $311,897.94$ & $318,198.91$ \\
\hline $\begin{array}{c}\text { Installed } \\
\text { capacity } \\
\text { (GWh) }\end{array}$ & $263,185.54$ & - & - & - & $286,565.93$ \\
\hline $\begin{array}{c}\text { Retired } \\
\text { capacity } \\
\text { (GWh) }\end{array}$ & $-7,002.62$ & $-7,809.40$ & $-4,953.68$ & $-3,268.85$ & $-8,427.54$ \\
\hline $\begin{array}{c}\text { Existed } \\
\text { capacity } \\
\text { (GWh) }\end{array}$ & $263,185.54$ & $255,376.14$ & $250,422.46$ & $247,153.61$ & $278,138.39$ \\
\hline $\begin{array}{c}\text { EEDP case } \\
\text { at 15\% } \\
\text { reserve } \\
\text { (GWh) }\end{array}$ & $220,374.50$ & $228,526.55$ & $237,280.25$ & $241,220.08$ & $247,828.85$ \\
\hline $\begin{array}{c}\text { Saving } \\
\text { capacity }\end{array}$ & - & $23,380.39$ & $38,299.73$ & $48,712.40$ & $31,632.98$ \\
\hline $\begin{array}{c}\text { Capital Cost } \\
\text { (Bath/KWh) }\end{array}$ & 1.31 & 1.40 & 1.44 & 1.46 & 1.45 \\
\hline $\begin{array}{c}\text { Saving cost } \\
\text { (M.Bath) }\end{array}$ & - & $32,708.37$ & $55,289.02$ & $71,033.17$ & $45,997.03$ \\
\hline
\end{tabular}

\section{Conclusion}

From this analysis under EEDP case, it is created to reduce electricity demands about $142,020.50 \mathrm{GWh}$, or 205,027.59 Million Bath in saving costs from 2014 to 2018. This paper 
can show that reducing of electricity demands under Energy Efficiency Development Plan (EEDP) is beneficial to utilities because utilities can ignore unnecessary investments from installing of new power plants. These not only create saving costs directly to utilities but also increase energy security in the future, including reduction of $\mathrm{Co}_{2}$ emissions. Therefore, utilities should have cooperation to support end users to reduce their electricity demands.

\section{References}

[1] Thai Government, 2011.Thailand 20-Year Energy Efficiency Development Plan (2011 - 2030): Ministry of Energy.

[2] Timothy J. Brennan and Karen Palmer, 2012. EnergyEfficiency Resource Standards: Economics and Policy: Washington, DC.

[3] Steven Nadel, 2006. Energy Efficient Resource Standards: Experience and Recommendations: American Council an Energy-Efficient Economy, p.21-22.

[4] Thai Government, 2010. Summary of Thailand Power Development Plan 2012-2030 (PDP2010: Revision3): Ministry of Energy

[5] Chadinee Kongrahad, (2011). Levelized Cost of Electricity Generation: Least Cost and least $\mathrm{Co}_{2}$ Emission Scenarios: JGSEE AT King Monkut's University of Technology Thonburi,Thailand 